\title{
Yükseköğretimde Mavi Okyanuslar
}

\author{
Şafak Gündüz \\ Maltepe Üniversitesi, İsletme ve Yönetim Bilimleri Fakültesi. ORCID: 0000-0002-2589-8780
}

\begin{abstract}
Özet
İşletme disiplininin son zamanlarda giderek önem verdiği araștırma konularından biri yoğun rekabet savaşlarına sahne olan kızıl okyanuslardan kaçarak yeni mavi okyanuslara yelken açmaktır. Bu da ancak Rene ve Mauborgne (2004) tarafından ileri sürülen Mavi Okyanus Stratejisi ile mümkün gözükmektedir. Mavi okyanus stratejisi; ileri sürüldüğü tarihten bu yana sadece işletme disiplinin tekelinde kalmayıp, birçok alanda yoğun bir biçimde ele alınmıștır. Kavram ile ilgili İșletme alanında Türkçe yazında da oldukça çalıșma bulunmaktadır. Ancak Türkçe yazında eğitim alanında konuyla ilgili yeterli çalışmanın olmaması bir eksiklik olarak tespit edildiğinden, özellikle yeniliklere çok açık olmak durumunda olan yükseköğretimin de Mavi Okyanus Stratejisinden faydalanabilmesi amacıyla bu çalışma yapılmıştır. Çalışmada aslında zaten yükseköğretimde uygulanmakta olan bu stratejinin örnekleri verilerek farkındalığın arttırılması sağlanacaktır. Çalışmanın; yükseköğretim alanında çalışmalar yapan araştırmacılara, uygulayıcılara, yöneticilere ve karar alıcılara ve yöneticilere rekabetin arttığı eğitim alanında yol gösterici nitelikte olması amaçlanmıștır.
\end{abstract}

Anahtar Kelimeler: yükseköğretimde mavi okyanus; mavi okyanus stratejisi; inovasyon; değer yaratma; kızıl okyanus

\section{Blue Oceans in Higher Education}

\begin{abstract}
The weariness of competitive business environment has made it one of the hot topics of recent business management literature to find ways to escape from the intense Red Ocean by creating a Blue Ocean where there is no competition. Rene and Mauborgne's Blue Ocean Strategy (2004) provides a reasonable solution for this issue. Blue Ocean Strategy has been dealt not only in Business Administration but also in many. There are also many studies in Business discipline Turkish literature on this concept. This study addresses the void in education area to enable the practitioners of higher education, which is subject to many innovations and changes to benefit from the strategy itself. The study aims to increase awareness toward Blue Ocean Strategy by demonstrating the best practices of the strategy in higher education. The study intends to generate insights for higher education academics, practitioners, managers and policy makers.
\end{abstract}

Key Words: blue ocean in higher education; blue ocean strategy; innovation; value creation; red ocean

\section{Giriş̧}

Örgütlerin yüksek karlılık, pazar payı artışı ve büyüme isteği kaçınılmaz bir şekilde yoğun bir rekabetin yaşanmasına yol açmaktadır. Bu durumda da ortaya çıkan rekabet için "kanlı savaş", bu akan kanların oluşturduğu durum için ise "kızıl okyanus" metaforu kullanılmaktadır. Kızıl okyanuslarda galipler ve mağluplar vardır ve bitip tükenmek bilmeyen bir rekabet söz konusudur. Bu yorucu rekabeti bir kenara bırakarak yeni ve keşfedilmemiş alanlara yönelen örgütler potansiyellerini daha fazla ortaya çıkarabilmektedir. Örgüt ve müşteriler için yeni ve farklı değerler yaratarak rekabetin oyun dışı kalmasını

*Yazışma Adresi / Address for Correspondence:

Şafak Gündüz, Email: safakgunduz@maltepe.edu.tr

Geliş Tarihi / Received Date: 15.11.2018

Kabul Tarihi / Accepted Date: 03.12.2018

Doi: $10.26701 /$ uad. 483514 sağlayan Mavi Okyanus Stratejisi; bu çalışmanın konusunu oluşturmaktadır. Bu stratejinin doğuşu, ne olduğu ve kullanıldığı alanlar ele alındıktan sonra yükseköğretimdeki yeri ve uygulanabilirliği örnekleriyle irdelenecektir.

\section{MAVI OKYANUS STRATEJISI}

Fransa INSTEAD Üniversitesi öğretim üyelerinden W. Chan Kim ve Renee Mauborgne tarafindan 2004 yılında yazılan "Mavi Okyanus Stratejisi - Çekişmesiz Pazar Alanı Yaratmak ve Rekabeti Etkisiz Kılmak" (Blue Ocean Strategy - How to Create Uncontested Market Space and Make the Competition Irrelevant) adlı kitapta ileri sürülen Mavi Okyanus Stratejisi aslında birçok örgüt tarafından uygulanan, ancak adı bu yazarlara kadar konulmamış bir stratejidir (Kim ve Mauborgne, 2014; Becker, 2013; Lindic vd., 2012). Yazarların 30 farklı sektördeki 100 yılı aşkın (1880-2000 arası) bir sürede gerçekleştirilen 150 stratejik faaliyet üzerinde yaptıkları çalışma mavi okya- 
nus stratejisi, yani bir tür kazan-kazan (win-win) stratejisi belirleyerek örgütleri köpek balıklarının parçaladığı kanlı kızıl okyanus tuzağına düşmekten ne şekilde kurtulduklarını birçok örnek ile gözler önüne sermektedir. İşletme disiplininde uzun zamandır kullanılmakta olan bu stratejiyi öğretmek ve mavi okyanus stratejisti mezun etmek amacıyla kurulan lisansüstü programları dahi bulunmaktadır (Mohammed, 2009).

Kendilerine bu stratejiyi neden "k1zıl" ve "mavi” renkler ile tanımladıklarının sorulduğu bir röportajda Kim ve Mauborgne; boğazların kesilip kan akıtıldığı rekabet savaşlarını "kızıl"1 rengi ile nitelendirdiklerini, ve derin, uçsuz bucaksız bu rekabet alanının da bir okyanusa benzetebileceğini belirtmişlerdir. Bu bağlamda mavi okyanus da henüz keşfedilmemiş, örgütlerin kendi niş pazar alanlarını yaratabilecekleri, kan akmayacağı için mavi olarak kalabilecek okyanusun ifadesidir (Mi, 2015). Her iki okyanusun da karşılaştırmasını Tablo 1'deki gibi yapmışlardır.

Tablo 1. Kızıl Okyanus-Mavi Okyanus Karşılaştırması

\begin{tabular}{|c|c|}
\hline KIZIL OKYANUS & MAVi OKYANUS \\
\hline Mevcut pazarda rekabet et & $\begin{array}{c}\text { Rekabetin olmadığı yeni pazarlar } \\
\text { keşfet, }\end{array}$ \\
\hline Rekabetle mücadele et ve galip gel & Rekabeti bir kenara bırak \\
\hline Mevcut talepten faydalan & Yeni talepler doğur \\
\hline Değer-maliyet dengesi gözet & Değer-maliyet dengesinin dışına çık \\
\hline $\begin{array}{c}\text { Örgütün tüm faaliyetlerini } \\
\text { farklılaşma veya düşük maliyet } \\
\text { üzerine kurgula }\end{array}$ & $\begin{array}{c}\text { Örgütün tüm faaliyetlerini } \\
\text { farklılaşma ve düşük maliyet } \\
\text { arasında denge kurarak gerçekleştir }\end{array}$ \\
\hline
\end{tabular}

Kaynak: Kim ve Mauborgne, 2005

Faaliyet gösteren örgüt sayılarının hızla artması, müşteri beklentilerine hızlı cevap verme ihtiyacı gibi sebepler, mavi okyanusta yeni talepler doğurulur. Mevcut talepler için savaşmak anlamsızdır (Kim ve Mauborgne, 2014). Farklllaşma ya da düşük maliyet stratejilerinden birini seçmek yerine "Hem-Hem" (yani her ikisi birden) stratejisi uygulanmaktadır. Talep; uğruna savaş verilmesi gereken bir unsur değil, yenilikçi bir biçimde yaratılması gereken bir unsurdur ve böylece rekabet anlamsız kalır (Kim ve Mauborgne, 2014).

Mavi okyanus yaratabilmenin dört yolu vardır: (Kim vd., 2006; Yang ve Yang, 2011)

- Müşteri için artık bir değer yaratmayan alanlardan vazgeçilmelidir.

- Müşteri için artık bir değer yaratmayan alanlar azaltılmalıdır.

- Standart üstü olan ve müşteri tatminini arttıran alanlara odaklanılmalıdır.

- Daha önce olmayan alanlarda talep yaratılmalıdır.

İngilizcede Eliminate (yok et), Reduce (azalt), Raise (arttır) ve Create (yarat) sözcüklerinin baş harflerinden oluşan ERRC Çerçevesi (Dört Eylem Çerçevesi) (Tablo 2) bu dört faaliyeti gerçekleştirmeden önce cevaplanması gere-

\footnotetext{
1 Kimi yazarlar "kırmızı okyanus olarak adlandırmaktadır.
}

ken soruları göstermektedir.

\begin{tabular}{|c|c|}
\hline \multicolumn{2}{|c|}{ Tablo 2. ERRC Çerçevesi } \\
\hline $\begin{array}{c}\text { Ele } \\
\text { Sektörün garanti olarak gördüğ̈̈ } \\
\text { hangi faktörler elenmelidir? } \\
\text { Gerektiğinde eleyin. }\end{array}$ & $\begin{array}{c}\text { Arttır } \\
\text { Sektör standardının üstünde kalan } \\
\text { hangi faktörler arttırılmalıdır? } \\
\text { A̧ıalt }\end{array}$ \\
\hline $\begin{array}{c}\text { Çayı yukarı çekin. } \\
\text { Sektör standardının altında kalan } \\
\text { hangi faktörler azaltılmalıdır? } \\
\text { Daha az ürün üretin. }\end{array}$ & $\begin{array}{c}\text { Sektörün daha önce öne sürmediği } \\
\text { hangi faktörler yaratılmalıdır? }\end{array}$ \\
\hline
\end{tabular}

Kaynak: Kim \& Mauborgne, 2005; Capital, 2005)

Yenilikçi değer yaratma mavi okyanusun en önemli unsurlarından biridir. Mavi Okyanus Stratejisi değer yaratmanı dört yenilikçi modelinden ${ }^{2}$ biridir (Güneş, 2011). Fayda, fiyat ve maliyet dengeleyen bir sistemin oluşturulması ile söz konusu olabilir (Ergen, 2011). Mavi okyanusta belli başlı prensipler şunlardır (Kim ve Mauborgne, 2015): (Şekil 1)

- Pazar sınırlarını genişletmek

- Mevcut talebin ötesinde düşünmek

- Değer-maliyet seçimi yapmadan ikisinin de birlikte olabileceğine odaklanmak

- Sayllardan çok büyük resme odaklanmak

- Doğru stratejik sıralamayı belirlemek

- Organizasyonel engelleri aşmak

- Strateji ile uygulamayı birleştirmek

Dr. Spencer Johnson'ın "Peynirimi Kim Kaptı" (Who Moved My Cheese) hikâyesi iş yaşamında her şeyin olduğu gibi yerli yerinde kalacağını düşünen, sorunlar için çözüm üretmekten çok durup söylenmeyi tercih eden stratejik yöneticilerin bir alegorisidir ${ }^{3}$ aslında. Değişime uyum sağlama yeteneğine gönderme yapılan masalın kahramanları, Kokarca ve Koklarca adlı iki küçük fare ve en az onlar kadar küçük olan Mırın ve Kırın adlı iki insancıktır (Johnson, 2009). Tüm yaşamlarını bir labirentin içinde her sabah giydikleri eşofmanla yola çlkarak peynirlerini aramakla geçirirler. Aralarındaki fark farelerin kemirgen güdüleriyle delikli, insancıkların ise inançla dolu beyinleriyle kendilerini çok farklı ve mutlu kılabilecek peynirleri aramalarıdır. İçgüdüleriyle koşup didinip, kafalarını duvara çarpa çarpa peynir arayan farelere karşın, akıllarını kullanarak her gün geliştirdikleri yeni yöntemlerle daha kolayca peynire ulaşan insancıkların farklı stratejileridir anlatılmak istenen. Akılca üstün olan insancıkların aklı küstahlığa dönüşür, rehavete kapılırlar ve azalan peynirin farkına varmazlar. Her gün gittikleri istasyonda peynirin azaldığının farkında olan fareler peynir bitince hiç şaşırmayıp vakit kaybetmeden yeni peynir arayışına çıkarlar. Oysa karmaşık inançlarıyla kendini sınırlandıran insancıklar "Peynirimi kim kaptı?”, "Ama bu haksızlık?" şeklinde tepkiler vererek zaman kaybetmektedir. Yeni peynir arayışına çıkmaları vakit aldığı gibi buldukları anda da yine "Ya kaybedersek?, "Ya yenisi bulamazsak?” vb. kay-

2 Dört yenilikçi strateji: mavi okyanus stratejisi, yıkıcı yenilik teorisi, ortak değer yaratma, tasarım tahrikli yenilik

3 Bir sanat eserindeki ögelerin gerçek hayattan bir şeyleri temsil etmesi durumu (Türk Dil Kurumu) 
gılara kapılırlar. Fareler ise her türlü değișikliğe daha kolay adapte olabilmektedir. İnsancıkların da labirent içinde değișime ayak uydurması nihayet gerçekleșir. Bu hikâye; yaptığımız iște ne kadar iyi olursak o kadar kör olduğumuzu ve bu sebeple tehlike ve firsatları kaçırdığımızın en güzel anlatımıdır. İște bu noktada devreye mavi okyanus stratejisi girmelidir (Gündüz, 2018; Johnson, 1998; Johnson, 2009; Becker, 2013).

Kim \& Mauborgne'a göre mavi okyanuslar cep telefonu, bioteknoloji, kargo, kafe vb. hemen hemen birçok endüstride çok uzun zamandır mevcuttur. Mavi okyanus stratejisinin sadece teknoloji alanında yenilik yapmak anlamına gelmediğini özellikle vurgulamaktadırlar. Her sektörde sizi rakiplerden farklı kılabilecek her türlü zeki hareket mavi okyanus stratejisi olarak değerlendirilebilir. Önemli olan klasik pazar rekabetinin dışında kalarak yeni alanlar bulmak ve geliștirmektir. P\&G, Samsung, Yellow Tail, Cirque de Soleil gibi birçok yabancı örgütün başarıyla uyguladığı bu stratejinin Türkiye'deki örneklerinden bazıları da Torku, Garanti Bankası, Freșa ve Ağaoğlu olarak gösterilebilir. Mavi Okyanus Stratejisi uygulayan Torku glikoz şurubu yerine şeker pancarı kullanmış, Garanti Bankası MiniBank'ı geliştirmiş, Freşa, maden suyunun acı tadını bastırsın diye meyveli sodayı çıkarmış, Ağaoğlu kriz zamanı fiyatı düșen arsaları düşük fiyata satın alarak rekabet avantajı elde etmiştir (Ağraş, Atbaş ve Şeyba, 2017).

Mavi okyanus stratejisi değer yaratmadan değer yenilikçiliğine doğru geçiş yapmayı ve farklılaşma ile maliyet liderliği stratejilerini eş zamanlı kovalayabilmeyi önermektedir (Giannoulis ve Zdravkoviç, 2012). Artık sektörün sınırları yeniden şekillendirilmektedir. Değer yenilikçiliği ile rakiplerin taklit ile kısa sürede nüfuz etmesi önlenebilecektir. Zira yenilikçi ve yaratıcı olmak taklit edilmesi en güç özelliklerdir (Chang, 2010). Bu sebeple üst yöneticiler hep değer yenilikçiliği üzerinde durmaktadır (Leavy, 1996). Mavi okyanuslar bulmak sadece yeni bir fikirle birdenbire ortaya çıkmak anlamına gelmemelidir. Geniş düşünmek, büyük resmi görebilmektir.

Örgütler artık Porter'ın Beş Gücü rekabet stratejisti ya da mavi okyanus stratejisti olma konusundaki seçimlerini yapmak durumundadır (Rau, 2012). Bir diğer deyișle ya acımasız rekabetin içinde kalacaklar, ya da yeni okyanuslara yelken açacaklardır. Bu seçimle ilgili hangisinin daha iyi olacağı ya da kimi durumda her ikisinin birden uygulanabilmesinin en doğru strateji olabileceğine ilişkin ampirik çalışmalar mevcuttur (Burke, Ster ve Thurik, 2009; Burke, Ster ve Thurik, 2010).

\section{YÜKSEKÖĞRETIMDE REKABET VE KIZIL OKYANUS}

Nüfus artışı, globalleşme, bilgi çağı, yeni teknolojiler, devlet reformları, yönetişim modelleri vb. (Aktan, 2007) değișiklik ve yeniliklere paralel olarak yükseköğretim kurumlarında da bir devinim mevcuttur. Benzerlikler sergi- lemekle birlikte çok eskiden beri farklı yapılarda karșımıza çıkan, sürekli yeni model ve yapılanma arayışı içinde olan yükseköğretim kurumları; aslında zaten bünyesinde bu anlamda bir rekabeti barındırmaktadır. Özellikle kurumsal itibarını ön plana çıkarmak, dünya çapında isim yapmak, akademik lig sıralamalarında üst kısımlarda yer almak isteyen ve toplumun şu anki ve gelecekteki beklentilerini en iyi biçimde karşılamak isteyen, ancak günün koşullarına bağlı olarak yoğun karmaşıklık ve belirsizlik ortamındaki üniversiteler bir anlamda kızıl okyanustaki kanlı savaşların birer parçasıdırlar (Öncel ve Sevim, 2014; Pucciarelli ve Kaplan, 2016).

Türkiye'de 2015 yllında Yükseköğretim Kalite Güvencesi Yönetmeliği kapsamında kurulan Yükseköğretim Kalite Kurulu'nun (YKK web sitesi) tüm yükseköğretim kurumlarından beklediği iç değerlendirmeyi takiben yapılan diş değerlendirmeye söz konusu performans göstergeleri, asıl niyet bu olmamakla, sadece kaliteyi yükseltmekle ilintili olmakla birlikte aslında bir anlamda rekabetin de göstergesidir. YKK'nin başkanı M. Elmas'a (2018) göre yükseköğretimde rekabet öne çıan alanlardan biri olmuştur.

Ayrıca Bilim, Sanayi ve Teknoloji Bakanlığı'nca hazırlanan “Türkiye'nin en girişimci ve yenilikçi üniversiteleri endeksi" de üniversitelerin rekabet etmesi gerektiğinin bir göstergesidir. Bilimsel ve Teknoloji Araştırma Yetkinliği, Fikri Mülkiyet Havuzu İşbirliği ve Etkileşim, Girişimcilik ve Yenilikçilik kültürü ve Ekonomik Katkı ve Ticarileşme olmak üzere beş kategoride değerlendirilen üniversiteler (Milliyet, 2013) mavi okyanuslarını bu alanlarda ön plana çıkarabilirler.

\section{YÜKSEKÖĞRETIMDE MAVI OKYANUS}

Yeni trend ve paradigmalar içindeki yükseköğretimde mavi okyanus stratejisinin uygulanabilirliği konusu tartışmalıdır (Dennis ve Lynch, 2015). Yükseköğretimde mavi okyanus stratejisi uygulamanın ancak bir mit olabileceği, ya da ancak özel eğitim kurumlarında uygulanabileceği de ileri sürülmektedir (Braganca, 2016).

Bilgi, bilim, eğitim ve topluma hizmet alanlarında hizmet veren üniversitelerin globalleșmenin zorunlu bir gereği olarak mobilizasyonu mümkün kılabilmek adına çeșitli akreditasyon kurulușları ya da devlet eliyle giderek standartlaştırılması, bir anlamda rekabet üstünlüğü sağlamanın önünde engel teşkil etmektedir. Üniversiteler giderek otonom yapılarını yitirmektedir. İşte bu noktada tam da devreye girmesi gereken Mavi Okyanus Stratejisidir. Rekabet alanının giderek daraldığı, manevra yeteneğinin azaldığı yükseköğretim arenasında artık üniversiteler mavi okyanus düşünce yapısına geçmelidir (Selskab, 2017). Yükseköğretimde rekabeti mavi okyanus ile daha etik boyuta da taşımak mümkün olabilir.

Yükseköğretimde yaratılabilecek mavi okyanuslar şu alanlarda olabilir: (Aktan, 2007) 
- Hizmetlerin sunumu (uluslararasılașma, harmonizasyon, akreditasyon, özelleştirme vb.)

- Yönetim (hesap verebilirlik, şeffaflık, sosyal sorumluluk, kurumsal yönetişim modeli, girişimci üniversite modeli vb.)

- Eğitim, öğretim ve öğrenme yöntemleri (e-öğrenme, yaşam boyu öğrenme, öğrenci merkezlilik, disiplinlerarası öğrenme vb.)

Bir Amerikan üniversitesi olan Vanderbilt'in mezunlarının birçoğunun iş bulmakta güçlük çekmesi konusunu derhal dikkate alıp, Mavi Okyanus Stratejisi takımı oluşturarak Kariyer Merkezleri çok etkin hale getirmesi, söz konusu stratejinin "Yarat" adımının uygulanmasının en güzel örneklerinden biridir (Blue Ocean Team, https:// www.blueoceanstrategy.com/blog/how-one-universityis-trying-to-break-out-of-the-redocean/). Bu üniversitenin bir Mavi Okyanus Stratejisi Ekibi (Blue Ocean Strategy (BOS) team) kurması bile bir yenilikçilik olarak değerlendirilebilir.

E-öğrenme alanında üniversiteyi her türlü erişebilir kılmak adına yapılabilecek ve öğrenciye değer yaratabilecek her yenilikçi uygulama Mavi Okyanus Stratejisi olarak değerlendirilebilir (Cohen vd., 2015).

Maltepe Üniversitesi'nin yönetim alanında Rektörü tarafindan yürütülen Ters Mentörlük de yine Mavi Okyanus Stratejisinin en güzel uygulamalarından biridir. Öğrenciye yetkinlikleri dahilinde inisiyatif tanıyan bu sistem aynı zamanda onların özgeçmişlerine de iş hayatı için zenginlik katmaktadır (Gündüz ve Akşit, 2018).

Sanayi-Üniversite işbirliği ile mezuniyet sonrası iş imkânı sunulması ve bunun stratejik bir model olarak benimsenmesi Mavi Okyanus Stratejisinin yükseköğretimdeki en belirgin örneklerinden biridir. Sabancı Üniversitesi bu stratejiyi uygulayan üniversiteye örnek olarak verilebilir.

Öğrenci tarafından tercih edilmeyen bölümlerin kapatılması mavi okyanusun "Yok et" uygulamasına örnektir.

\section{SONUÇ}

İş dünyasının her alanında yer alan, eğitim sektörünün de nasibini aldığı rekabet, özellikle eğitimde daha yüksek bir potansiyel açığa çıkarabilmek adına aslında uzak durulması gereken konulardan birisidir. Burada rekabetten uzak durmaktan kasıt, aslında yeni mavi okyanuslar keşfederek üstünlük sağlamak ve bu üstünlükte rekabette bir anlamda öne geçmektir.

Burada dikkate alınması gereken en önemli nokta mavi okyanusun da bir müddet sonra rakipleri çekeceği, buralarda da rekabetin başlayacağı ve hatta tekrar kızıl okyanusa dönüşebileceğidir. Ancak keşfedilmemiş bir alanda öncülük etmek, tam bir pazarlama tabiriyle "pazarın kaymağını yemek" (market skimming) anlamına gelir ve bu da örgütün karlılığında ve tanınırlığında önemli bir etkendir.
Sürekli rekabetin içinde olmak bir süre sonra cazip gelebilir. Bunun büyüsüne kapılan örgütler de bundan çok kolay kurtulamazlar. Oysa sürekli savaş alanında tutunmaya çalışanlar bir müddet sonra oluşan kızıl okyanusta boğulmaya mahkûm kalabilirler. Bunun yerine rekabete daha az yoğunlaşıp, yenilikçilik ve değer yaratmaya yönelmek beraberinde rekabet avantajını da kendiliğinden getirecektir.

$\mathrm{Bu}$ çalışmanın üniversitelerin stratejik yönetimlerinde Mavi Okyanus Stratejisine daha fazla yoğunlaşmaları adına farkındalık yaratacağı düşünülmektedir. Daha sonra yapılacak çalışmalarda üniversitelerin bu konudaki çalışmalarına ayrıntılı olarak yer verilebilir.

Ayrıca kızıl okyanus ve mavi okyanus stratejilerini beraber yürütmenin zorunlu olduğu günümüz koşullarında Yeşil Okyanus Stratejisi (Tantau ve Mateeşescu, 2013) çalışmalarına yönelinebilir.

\section{KAYNAKÇA}

Ağraş, S., \& Atbaş, F. (2017). Mavi Okyanus Stratejisi: Dünyadan ve Türkiyeden örnekler. JOMELIPS, 2(2), 126-144.

Aktan, C. C. (2007). Yükseköğretimde değişim: Global trendler ve yeni paradigmalar. Değişim çağında yükseköğretim (ss. 1-43). İzmir: Yaşar Üniversitesi Yayını.

Braganca, R. (2016). Blue ocean strategy for higher education. International Conferences ITS, ICEduTech and STE. 325-328.

Becker, H. (2013). IMAX move to Hollywood: Blue ocean strategy or a case of who moved my cheese. Global Conference on Business and Finance Proceedings, 8(2).

Blue Ocean Team (2015). How one university is trying to break out of the red ocean. Çevrimiçi: https://www. blueoceanstrategy.com/blog/how-one-university-is-trying-to-break-out-of-the-red-ocean/.

Burke, A., Ster, A., \& Thurik, R. (2009). Blue ocean versus competitive strategy: Theory and evidence. ERIM Report Series Reference No. ERS-2009-030-ORG. Çevrimiçi: https://ssrn.com/ abstract=2024822. Burke, A., Ster, A. \& Thurik, R. (2010). "Blue Ocean vs. Five Forces", Harvard Business Review.

Capital. (2005). Mavi okyanusta büyüme zamanı. Çevrimiçi: https://www.capital.com.tr/yonetim/liderlik/maviokyanusta-buyume-zamani

Chang, S. (2010). Banditt Cellphones: A blue ocean strategy. Technology in Society, 32, 219- 223.

Cohen, M. S., Snyder, M. M., Brocke, J., Dringus, L. P., \& Syler, R. A. (2015). The next decade of online learning in higher education: Blue ocean strategies for the design and delivery of graduate is programs. Twentyfirst Americas Conference on Information Systems, Puerto Rico.

Dennis, M., \& Lynch, R. (2015). Is higher education ready for blue ocean strategies? Çevrimiçi: http://www.universityworldnews.com/article.php?sto$r y=2015082513171120$

Elmas, M. (2018). Yükseköğretimde değişim zorunluluğu. Kriter, 
$3(7)$.

Ergen, A. (2011). Stratejik düşünce yaratma. Pazarlama ve Pazarlama Araştırmaları Dergisi, 7, 1-21.

Giannoulis, C. \& Zdravkoviç, J. (2012). Linking strategic innovation to requirements: A look into Blue Ocean Strategy. (Eds. Kurt Sandkuhl, Ulf Seigerroth \& Janis Stirna), November 7-8, 2016, Emerging Topics in the Practice of Enterprise Modelling 5thIFIP WG 8.1 Working Conference Proceedings, 118-128, Rostock.

Güçlü, A. (2013, 10 Nisan). En yenilikçi üniversiteler. Milliyet. Çevrimiçi: http://www.milliyet.com.tr/yazarlar/ abbas-guclu/en-yenilikci-universiteler-1691592/

Gündüz, Ş. (2016). How to make blue ocean turning into red ocean blue again: A case study of a room escape game. Proceedings of ADVED 2016 2nd International Conference on Advances in Education and Social Sciences 10-12 October 2016- Istanbul, Turkey.

Gündüz, Ş., \& Akşit, Ş. (2018). Student-President reverse mentoring at universities: Maltepe University Case. Journal of Higher Education, Kabul edilmiş ancak yayın sırasındaki makale.

Gündüz, Ş. (2018). Preventing Blue Ocean from turning into Red Ocean: A case study of a room escape game. International Journal of Human Sciences, 15(1), 1-7.

Güneş, S. (2011). Değer yaratma bağlamında güncel dört yenilik modeli. Sanat ve Tasarım Dergisi, 1(1), 71-89.

Johnson, S. (1998). Who moved my cheese? London: Ebury Publishing.

Johnson, S. (2009). Peynirimi kim kaptı? (Nazlı Uzunali, Çev.). İstanbul: Epsilon Yayınevi.

Kim, W. C., \& Mauborgne, R. (2004). Blue ocean strategy, Harvard Business Review, 82(10).

Kim, W. C., \& Mauborgne, R. (2005). Blue ocean strategy. How to create uncontested market space and make the competition irrelevant. Cambridge. MA: Harvard Business School Press.

Kim, W. C., \& Mauborgne, R. (2005). Blue ocean strategy: From theory to practice California Management Review, 47(3), 105-121.

Kim, W. C., Yang, K. H., \& Kim, J. (2006). A strategy for third-party logistics systems: A case analysis using the blue ocean strategy. Omega, 36(4), 522-534.

Kim, W. C., \& Mauborgne. R. (2014). Interview with Kim \& Mauborgne, authors of Blue Ocean Strategy. Çevrimiçi: moodle.technion.ac.il

Leavy, B. (1996). Design thinking - A new mental model of value innovation. Strategy \&Leadership, 38(3), 5-14.

Lindic, J., Bavdaz, M., \& Kovacic, H. (2012). Higher growth through the Blue Ocean Strategy: Implications for economic policy. Research Policy, 41, 928-938.

Mi, J. (2015). Blue ocean strategy. Wiley Encyclopedia of Management, 1-1.

Mohammed, Z. A. (2009). Analysis of the use of the blue ocean strategy, case study analysis on 14 different analysis, Research Bulletin of the Faculty of Economics. Çevrimiçi: econ.upm.edu.

Öncel, M., \& Sevim, Ş. (2014). Sürdürülebilir rekabet üstünlüğü sağlamada kurumsal itibar yönetimi: yükseköğretimde yapılandırılmasına yönelik bir model önerisi. İşletme Araştırmaları Dergisi, 6(4), 139156.

Pucciarelli, F., \& Kaplan, A. (2016). Competition and strategy in higher education: Managing complexity and uncertainty. Business Horizons, 59, 311-320.

Rau, J. G. (2012). With your idea, are you trying to navigate the red ocean or the blue ocean? Inventors' Digest, Çevrimiçi: InventorsDigest.com.

Selskab, V. (2017). Universities in the blue ocean. Çevrimiçi: www.royalacademy.dk/ /media/ Royal Academy /.../2017/Hvidbog-2017_UK.pdf ?la=da

Tantau, A. D., \& Mateeşescu, S. (2013). The green ocean innovation model. International Journal of Business, Humanities and Technology, 3(6), 59-65.

Türk Dil Kurumu, http://www.tdk.gov.tr/index.php?option=com_bts\&view=bts\&kategori1=veri tbn\& kelime $\sec =11300$

Yang, C. C., \& Yang, K. J. (2011). An integrated model of value creation based on the refined Kano's model and the blue ocean strategy. Total Quality Management \& Business Excellence, 22(9), 925-940.

YKK web sitesi, http://www.yok.gov.tr/web/kalitekurulu/komisyonlar 